\title{
El CLIL i l'ensenyament-aprenentatge de la ciència a primària
}

\author{
Conxa Sánchez \\ CEIP Sant Domènec, La Ràpita (Alt Penedès) \\ csanche6@xtec.cat
}

Es presenta la metodologia CLIL (aprenentatge integrat de continguts i llengües estrangeres), adreçada tant a ensenyar ciències com a aprendre una llengua estrangera, l'anglès, a primària.

Paraules clau: CLIL, aprenentatge integrat de continguts i llengües estrangeres, anglès, ciències, contingut, comunicació, cognició, cultura, currículum

El curs 2006-07 vaig estar a Anglaterra amb una llicència d'estudis $C$ per desenvolupar un projecte relacionat amb l'ensenyament-aprenentatge de la ciència en Anglès.

El coneixement del currículum anglès de ciència, juntament amb l'observació de com es treballa a les escoles angleses, la metodologia CLIL i l'assistència a un curs de formació impartit pel Centre de Documentació i Experimentació de Ciències (CDEC, s.d.) van fer que la meva perspectiva sobre l'ensenyament-aprenentatge de la ciència, canviés radicalment i passés d'un projecte basat en un reguitzell d'experiments, al disseny de dues unitats de programació on la utilització del mètode científic és -o pretén ser- l'eix vertebrador de les dues unitats. Vegem unes quantes pinzellades sobre el CLIL.

\section{Introducció}

No és cap secret per a ningú que des de ja fa uns quants anys l'anglès s'utilitza com a "lingua franca" en un món cada dia més globalitzat; en conseqüència, es fa necessari el coneixement d'aquest idioma. També sabem que, malgrat alguns avenços, a casa nostra els alumnes no en tenen un domini gaire alt quan acaben l'ensenyament obligatori.

Per intentar canviar aquesta situació, des del Departament d'Educació s'ha escoltat la demanda de la societat i seguint la dinàmica marcada per al- gunes escoles s'han anat potenciant diferents iniciatives a Primària. Recordem-les: començar l'aprenentatge d'aquest idioma als 8 anys i des de no fa gaires cursos, la generalització de la introducció de la llengua anglesa a primer de cicle inicial, és a dir, als 6 anys.

Des de fa temps, i per iniciativa pròpia, moltes escoles hem avançat aquest començament a Infantil. I finalment, i anant un pas més enllà, les mateixes escoles o altres hem introduït la utilització de l'anglès com a llengua d'ensenyament-aprenentatge de determinats temes del currículum de diferents àrees com les d'Educació Plàstica i Artística, Educació Física, Coneixement del medi natural, Matemàtiques, etc., amb el recolzament del Departament, mitjançant els programes d'innovació, beques d'estada a Anglaterra i cursets a la universitat de Nottingham.

Aquesta última iniciativa està lligada al que es coneix com CLIL en anglès i AICLE en la seva versió espanyola.

\section{Què és el CLIL?}

Aclarirem primer aquests dos acrònims: CLIL (Content and Language Integrated Learning), AlCLE (Aprendizaje Integrado de Contenidos y Lenguas Extranjeras).

Farem una mica de història. Simplificant molt, el CLIL es va originar a Europa a partir de la contribució de diferents investigadors, lingüistes i profes- 
sors a mitjans dels 90, amb la voluntat d'emparar qualsevol tipus d'activitat en l'àmbit educatiu en que una llengua estrangera és utilitzada en l'ensenyament-aprenentatge d'un contingut no lingüístic amb un doble objectiu: usar la llengua estrangera per aprendre, i aprendre a usar la llengua estrangera.

No és tracta, doncs, d'un altre mètode d'ensenyar una llengua, sinó d'un altre mètode d'aprendre una llengua.

El CLIL és flexible i dinàmic i sota aquests termes podem trobar diferents modalitats que comparteixen el mateix principi: contingut i llengua d'aprenentatge estan íntimament lligats.

A continuació fem a grans trets el llistat d'alguns d'aquests models:

- Projectes globals com els organitzats per Science across the world, on alumnes de diferents països estudien els mateixos temes (escalfament global, energies renovables, etc.) en diverses llengües i més tard comparen els resultats.

- Treballar alguns eixos transversals del currículum, com ara el comerç just, valors de la pau, determinats pintors o músics, etc. Dins d'aquesta modalitat podríem incloure algunes experiències portades a terme al País Basc.

- Ensenyar-aprendre determinats continguts corresponents a qualsevol àrea no lingüística del currículum de Primària o Secundària. Aquest és el cas de les diferents experiències d'algunes escoles catalanes.

- L'opció d'escola bilingüe com el CEIP Vila Olímpica de Barcelona (en el seu cas, trilingüe perquè es tracta de les tres llengües: català, espanyol, anglès, una de les opcions més radicals, avui per avui minoritàries).

\section{Metodologia CLIL}

Qualssevol de les modalitats CLIL que es triïn parteixen des de bon començament que és el contingut a treballar el que lidera el camí a seguir, és l'eix fonamental a partir del qual s'elaboren els objectius, les activitats i el llenguatge que utilitzarem. D'aquí la paraula integrar contingut i llengua.

Els quatre principis bàsics de la metodologia CLIL són:

\section{Content}

L'adquisició d'un determinat coneixement implica l'assoliment d'uns objectius i de les habilitats i estratègies pròpies d'aquest coneixement. Tot això configura el que anomenem contingut.

En cap moment es pot plantejar rebaixar els continguts en funció de la llengua que s'utilitza. És força desitjable l'existència d'una bona coordinació i entesa entre el professor d'anglès i el tutor en el cas de Primària, treballant i esperant perquè en un futur no molt llunyà qualsevol tutor de primària pugui fer classes de qualsevol àrea en anglès.

Si parlem de Secundària, caldria un professor de determinada especialitat que a la vegada fos competent en anglès.

\section{Communication}

S'utilitza la llengua com una eina de comunicació i aprenentatge. No es tracta en cap moment d'una classe de llengua estrangera. Això si: cal facilitar als alumnes els suports visuals i els frames o models lingüístics que necessitin, però sense entrar en els aspectes gramaticals.

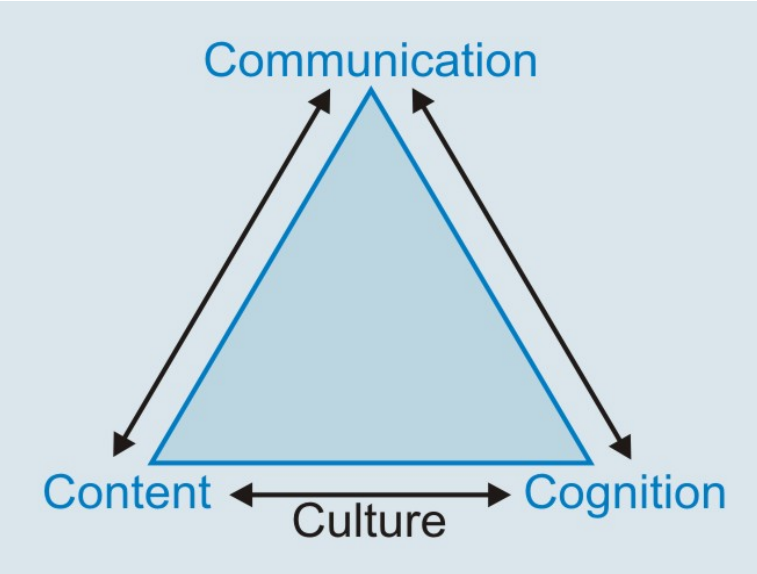

\section{Cognition}

Perquè sigui efectiu, el CLIL planteja un repte als alumnes: pensar i construir el seus propis aprenentatges. No parlem doncs, de transmetre coneixements d'un expert, el mestre, a un novell, l'alumne. El paper dels ensenyants és ajudar i facilitar les eines perquè això sigui possible.

Al dissenyar les diferents activitats o tasques a realitzar pels alumnes, convé assegurar que impliquin un repte cognitiu, és a dir, que no siguin massa simplistes però permetin anar progressant als alumnes.

\section{Culture}

En el món multicultural i globalitzat en que vivim, la tolerància i la comprensió son factors bàsics; d'aquí la necessitat de potenciar el respecte a "l'altre" i a les diferències. 


\section{Avaluació}

El que s'avalua és el contingut. Això es pot fer de diverses maneres depenent del tema treballat: diagrames, omplir buits, corregir falses interpretacions, escollir entre dues opcions, gràfics, mapes de conceptes, activitats concretes de classe, autoavaluacions, etc.

\section{EI CLIL i l'ensenyament-aprenentatge de la ciència}

Em preguntareu què pot aportar el CLIL a l'ensenyament-aprenentatge de la ciència. A continuació intentaré explicar, des del meu punt de vista, quina o quines poden ser les seves contribucions, algunes d'elles més aviat indirectes, ja que es tracta d'una metodologia amb vocació general, adreçada a totes les edats i amb una especial sensibilitat pel que fa al tema de la llengua com a eina de comunicació i aprenentatge.

Les implicacions del CLIL, que tenen a veure amb aspectes lingüístics són molt importants però, potser surten una mica del que ens interessa tractar aquí. És per aquesta raó que no esmentaré, més enllà del que ja he apuntat anteriorment, la necessitat de donar suport lingüístic als nostres alumnes en funció del contingut a treballar, és a dir, d'usar la llengua.

El Departament d'Educació ha apostat de manera decidida per aquesta metodologia i ha possibilitat el seu coneixement, la seva popularització $\mathrm{i}$ influència mitjançant cursets a Catalunya i a la universitat de Nottingham (School of Education, professora Do Coyle i altres) apart de les llicències $\mathrm{C} \mathrm{a}$ Anglaterra.

Degut als vincles amb la universitat de Nottingham $\mathrm{i}$ amb el sistema educatiu anglès $\mathrm{i}$ molt possiblement sota la influència del seu currículum de ciència i de l'observació de com aquesta es treballa a les escoles angleses, bona part del material que hem anat elaborant mestres catalans referents a ciència, té molt present la forma d'entendre l'ensenyament-aprenentatge d'aquesta àrea. Entre altres afirmacions, el currículum anglès (Currículum anglès, s.d.) de ciència de primària diu:

\section{Children should:}

-develop skills of predicting, asking questions, making inferences, concluding and evaluating based on evidence and understanding and use these skills in investigative work

-use scientific and mathematical language including technical vocabulary and conventions, and draw diagrams and charts to communicate scientific ideas.

Així doncs, ens trobem amb una metodologia que situa l'eix central de l'ensenyament-aprenentatge de la ciència en l'observació, la comparació, la classificació, la predicció, l'experimentació, la interpretació, la comunicació de conclusions,el diàleg, la discussió, etc., és a dir, la utilització del mètode científic que permet el desenvolupament de les habilitats intel.lectuals dels alumnes.

Un altre aspecte que el CLIL potencia des del vessant metodològic és la importància de fer preguntes rellevants que comportin anar una mica més enllà de la descripció empírica d'un fet o fenòmens del món natural o físic i que possibilitin la construcció de coneixement, com ara totes les preguntes relació causa-efecte, les que impliquen per contestar-les una reflexió, en la mesura que la verbalització ajuda a construir i a reforçar la comprensió d'un fenomen, les que ajuden a descobrir canvis, les que fan referència a les prediccions, etc.

Per aclarir una mica més tot el que acabo d'exposar us presento, a la pàgina següent, un exemple de com s'ha planificat una lliçó CLIL de ciència. Aquesta en concret l'ha dissenyada la Marta Hernández i forma part del seu material Plants, que es pot consultar a l'adreça web del Departament on hi ha penjats aquests $i$ altres materials CLIL de Primària i Secundària.

Per finalitzar, només comentar que personalment penso que la metodologia CLIL pot ser útil per complir dos objectius: ensenyar i aprendre ciència d'una altra manera i millorar l'anglès dels nostres alumnes mitjançant l'ús d'aquesta llengua en un context real.

\section{Bibliografia}

APAC (2005). CLIL in Catalonia, from Theory to Practice. APAC Monographs, 6

CDEC (Centre de Documentació i Experimentació en Ciències) (sense data). Curs per a l'actualització de l'ensenyament / aprenentatge de les ciències naturals. (Programa de formació en ciències cursos 2003-2004 i 2004-2005).

http://www.xtec.es/formacio/matform/cienciespri maria/ponencies/index.htm

Coyle, D. (2005). Content and Language Integrated Learning. Motivating Learners and Teachers. University of Nottingham

Currículum anglès (sense data) de ciències de Primària www.nc.uk.net/webdav/harmonise 
Departament d'Educació. Materials CLIL elaborats per professors catalans de Primària i Secundària

http://www.xtec.cat/crle/pla_le/cataleg.htm-

http://www.xtec.cat/crle/pla_le/catalegnot_pri.ht

$\mathrm{m}$ 
Un exemple de lliçó CLIL de ciència

per al Cicle superior de Primària

\section{CLIL LESSON PLAN}

\section{PLANTS}

TOPIC: PLANTS ARE LIVING THINGS

\section{AIMS}

1.- To understand and explain why plants are living things

2.- To understand and explain what plants need to grow

\begin{tabular}{|c|c|c|c|}
\hline $\begin{array}{l}\text { TEACHING } \\
\text { OBJECTIVES }\end{array}$ & $\begin{array}{l}\text { LEARNING } \\
\text { OUTCOMES }\end{array}$ & \multirow[t]{2}{*}{ COMMUNICATION } & \multirow{2}{*}{$\begin{array}{l}\text { CULTUREI } \\
\text { CITIZENSHIP }\end{array}$} \\
\hline A.- CONTENT & A. CONTENT & & \\
\hline $\begin{array}{l}\text { To give an introduction to } \\
\text { plants by offering: } \\
\text { - } 4 \text { reasons why they } \\
\text { are living things } \\
\text { - } 4 \text { elements plants } \\
\text { need to grow }\end{array}$ & $\begin{array}{l}\text { Pupils will have/be able } \\
\text { to : } \\
\text { - Memorized key voca- } \\
\text { bulary } \\
\text { - Justify why plants are } \\
\text { living things } \\
\text { - Say what plants need } \\
\text { to grow }\end{array}$ & \multirow{3}{*}{$\begin{array}{l}\text { Language of learning: } \\
\text { - } \quad \text { Key vocabulary } \\
\text {-reasons for being liv- } \\
\text { ing things } \\
\text {-elements plants } \\
\text { need to grow } \\
\text { Language for learning: } \\
\text { - Language to answer } \\
\text { questions } \\
\text {-Plants are living } \\
\text { things because... } \\
\text {-Plants need to } \\
\text { grow... } \\
\text { - Language to express } \\
\text { their predictions } \\
\text {-I think it will be a } \\
\text { healthy plant with... } \\
\text {-I think it will... } \\
\text { - Language to express } \\
\text { their conclusions } \\
\text {-Finally what has } \\
\text { happened is that the } \\
\text { plant ... } \\
\text { Language through learn- } \\
\text { ing: } \\
\text { - Language to carry out } \\
\text { worksheet tasks }\end{array}$} & \multirow[t]{3}{*}{$\begin{array}{l}\text { Pupils will appreciate bet- } \\
\text { ter: } \\
\text { - How to take care } \\
\text { plants and why that is } \\
\text { important } \\
\text { - How to be responsible } \\
\text { and accurate in carry- } \\
\text { ing on an investigation }\end{array}$} \\
\hline B. COGNITION & B. COGNITION & & \\
\hline $\begin{array}{l}\text { To allow opportunities for } \\
\text { pupils to discuss and de- } \\
\text { cide: } \\
\text { - why plants are living } \\
\text { things } \\
\text { - what plants need to } \\
\text { grow } \\
\text { - how to carry out an in- } \\
\text { vestigation }\end{array}$ & $\begin{array}{l}\text { Pupils will be able to: } \\
\text { - Apply memorized key } \\
\text { vocabulary in different } \\
\text { contexts } \\
\text { - Use predictions to } \\
\text { state what seeds need } \\
\text { to grow into a healthy } \\
\text { plant and what is } \\
\text { going to happen to a } \\
\text { plant in different situa- } \\
\text { tions } \\
\text { - Use deduction to con- } \\
\text { firm the above }\end{array}$ & & \\
\hline
\end{tabular}

